\title{
MiR-324-5P Functions as a Novel Serum Biomarker and Modulates Breast Cancer Malignant Activity
}

\author{
Jiling Zhang \\ Shaoxing People's Hospital \\ Yanyan Zhang \\ Shaoxing People's Hospital \\ Shanmei Lv \\ Shaoxing People's Hospital \\ Huiying Wang \\ Shaoxing People's Hospital \\ Lu Gao \\ Shaoxing People's Hospital \\ Xuejun Dong ( $\nabla$ dxj9666@qq.com ) \\ Shaoxing People's Hospital
}

\section{Research Article}

Keywords: Breast cancer, miR-324-5p, molecular mechanism, biomarker

Posted Date: December 28th, 2021

DOI: https://doi.org/10.21203/rs.3.rs-1165299/v1

License: (c) (i) This work is licensed under a Creative Commons Attribution 4.0 International License.

Read Full License 


\section{Abstract}

Introduction: The best management practices for patients with breast cancer $\mathbb{B C} \mathbb{C}$ involve early detection and deterioration prevention. Therefore, it is important to study the occurrence of $\mathrm{BC}$ and its development mechanism and explore more sensitive diagnostic and prognostic indicators.

Objective: Our study explored the significance and the serum miR-324-5p application in the diagnosis and prognosis of $\mathrm{BC}$ and evaluated possible molecular mechanisms.

Methods: MiR-324-5p expressions in the serum and tissue of patients with BC were observed by real-time fluorescence quantitative polymerase chain reaction (PCR). Next, the miR-324-5p diagnostic ability in BC was evaluated by the receiver operating characteristic curve. Kaplan-Meier analyzed the relationship between expression of miR-324-5P and prognosis. The Cox regression model evaluated the serum miR324-5P prognostic value in predicting disease-free survival (DFS) and overall survival (OS). In functional studies, cell counting Kit-8 assay and Cloning experiment were employed to assess BC cells' proliferation level. Transwell assays and wound healing assays were performed to determine the effect of miR-324-5p on $\mathrm{BC}$ cell invasion and migration. In addition, the flow cytometry test was conducted to determine the effect of miR-324-5p on the apoptotic rate of BC cells. Finally, bioinformatics tools were employed to detect the potential target genes of miR-324-5p in BC.

Results: miR-324-5p expression is up-regulated in in BC cells, which is related to tumor stage $\triangle p=0.0291)$ and age $(p=0.0278)$. In addition, a BC diagnosis based on serum miR-324-5p levels had an $66 \%$ sensitivity, $78 \%$ specificity, and the area under the curve was approximately 0.7581 . DFS $(p=0.027)$ and OS $(p<0.017)$ in the low miR-324-5P expression group were higher than those in the high expression group. The tumor node metastasis staging $\square \mathrm{Ki}-67$ and miR-324-5P were independent prognostic factors for the survival of patients with BC. In addition, miR-324-5p had a positive effect on BC cell invasion and proliferation, thereby preventing apoptosis. Finally, bioinformatics synthesis showed that the miR-324-5p target genes in $\mathrm{BC}$ are cysteine-rich hydrophobic domain 1 (CHIC1) and kruppel-like factor 7 (KLF7).

Conclusion: MiR-324-5p may perform its oncogenic functions by interacting with the CHIC1 and KLF7 genes, and its existence in serum could serve as a diagnostic and prognostic biomarker of BC.

\section{Introduction}

Breast cancer (BC), is one of the most common malignancies in women and a leading cause of death in the 21st century. It is expected to become a primary obstacle to extended life expectancy [1]. However, there is a lack of accurate and early diagnostic and screening methods because of limited progress in BC molecular mechanisms determination. Thus, many patients with $\mathrm{BC}$ missed the opportunity for radical resection [2]. Therefore, studies should focus on BC molecular mechanisms to determine new biomarkers capable of identifying and predicting genes as potential treatment targets. 
Micro-ribonucleic acid (miRNA) is a non-coding RNA composed of 21-25 nucleotides, widely distributed in the mammalian genome [3]. Thus far, the cancer cells regulation by miRNAs has been identified in many processes, such as cell proliferation, apoptosis [4], angiogenesis [5], radiosensitivity [6], and migration [7]. The miRNAs abnormal expression in malignant tumors would impact the carcinogenic expression or tumor suppressor genes during tumorigenesis and metastasis [8]. Research has revealed that miR-937-5p overexpression can regulate the cell proliferation and cell cycle via the Wnt signaling pathways [9]. Noyans et al. found that the miR-770-5p down-regulation could explain the epithelial-mesenchymal transition in BC [10]. Overall, these studies revealed the miRNAs important role in BC. Hence, abnormal miRNA expression may be a good biological marker for BC diagnosis and prognosis; besides, the involved miRNAs may also serve as potential treatment targets.

MiR-324-5p has been shown to either inhibit or promote human cancer. For example, it is inhibitory for gallbladder [11] and colorectal cancer [12] but can show carcinogenic effects in thyroid papillary [13], pancreatic [14], and gastric cancer [15]. However, whether the expression levels of miR-324-5p can serve as a predictor for $B C$ development remains to be revealed. Therefore, this study evaluated the miR-324-5p relative expression levels in the serum and tissues of patients with $\mathrm{BC}$ and studied the correlation between the miR-3324-5p expression levels and patients with BC clinicopathological features. In addition, the miR-324-5P feasibility as a marker for BC diagnosis and prognosis was evaluated. Finally, we studied miR-324-5p for its functional effects on BC and analyzed its potential target genes.

\section{Methods And Materials}

\subsubsection{Collection of clinical samples}

Serum samples include 100 serum samples of BC patients and 50 healthy control sera from Shaoxing People's Hospital.. Among them, the patient was newly diagnosed as a female patient with BC, aged 27 to 73 years old. Blood was collected from all patients before they received any form of treatment. Collect whole blood into anticoagulant blood collection tubes. Following that, the tubes were gently inverted 4 to 5 times to mix the anticoagulant with the blood. Quickly transfer to a separate cryopreservation tube or centrifuge tube, store in $-80^{\circ} \mathrm{C}$ refrigerator.

The tissue samples included 41 pairs of $B C$ and adjacent tissues obtained from female patients, all of which were newly diagnosed BC in Shaoxing People's Hospital,aged 35 to 72 years. The tissue specimens were quick-frozen in liquid nitrogen within 30 minutes of in vitro and then transferred to the $-80^{\circ} \mathrm{C}$ refrigerator for storage.All experimenters signed a written informed consent form.

\subsubsection{Cell culture}

Human BC cell lines T-47D, MCF-7, Hs578T and non-tumorigenic epithelial cell line MCF-10A are provided by the Cell Resource Center of Shanghai Institute of Biological Sciences, Chinese Academy of Sciences. Among them, MCF-10A cells use DMEM/F12 medium (Gibco), and additionally add $5 \%$ horse 
serum (HyClone), insulin, epidermal growth factor, and hydrocortisone. Other cell lines use DMEM medium with $10 \%$ fetal bovine serum (Hyclone). All cells were cultured at $37^{\circ} \mathrm{C}$ and $5 \% \mathrm{CO}_{2}$.

\subsubsection{Transfection}

$3 \times 10^{5} \mathrm{MCF}-7$ cells were inoculated in one well of the six-well plate. These were then transfected at a final concentration of $50 \mathrm{nM}$ miR-324-5p mimics or with the appropriate miRNA mimic control using lipofectamine 6000 transfection reagent (Beyotime Biotechnology). The Hs578T cells were seeded at $2 \times 10^{5}$ cells per well into 6-well plates and were transfected with miR-324-5p inhibitors at a final concentration of $100 \mathrm{nM}$ or with the appropriate miRNA inhibitor control using Lipofectamine 6000 transfection. All subsequent functional assays were performed $48-72 \mathrm{~h}$ post-transfection. Guangzhou RiboBio provides transfection reagents.

\subsubsection{RNA isolation and quantitative real-time PCR (RT-qPCR)}

We chose to use Trizol (Haoxin) to collect total RNA from cultured cells and tissues. Serum miRNAs was harvested from each $200 \mu \mathrm{l}$ serum sample by using a Serum/plasma miRNA extraction and separation kit (TianGen). The total RNA then underwent reverse transcription using Prime ScriptTM RT reagent Kit with gDNA Eraser. For microRNAs detection, stem-loop RT-PCR was carried out by using the cDNA product as templates by SYBR ${ }^{8}$ Premix Ex Taq ${ }^{\text {TM }}$ (TaKaRa) in the Light Cycler 480 System (Roche Diagnostics). For internal reference, primers of U6 and U6. miR-324-5p were obtained from RiboBio.

\subsubsection{Cell Counting Kit-8 tests}

48 hours after transfection, MCF-7 cells and Hs578T cells were seeded in several 96-well culture dishes at 1000 and 3000 cells/well, respectively. Cell Counting Kit-8 (CCK-8, MedChemExpress) tests the cell growth rate at different times.

\subsubsection{Cloning experiment}

48 hours after transfection, MCF-7 cells and Hs578T cells were inoculated in several 6-well culture dishes with 1000 cells/well, respectively. After 10 days of culture, the cells were stained with crystal violet and counted.

\subsubsection{Wound healing assay}

When the cell density after transfection reaches $90-95 \%$, Scratch with $200 \mu \mathrm{l}$ grab head and wash the residual cells on the scratch with sterile PBS. Then, add fresh medium with $1 \%$ FBS into the 6-well plates, and microscopic images were taken over the plates at 0-24 $\mathrm{h}$. The wound healing rates were calculated and compared to the width at $0 \mathrm{~h}$.

\subsubsection{Transwell assay}


For migration assays, MCF-7 cells and Hs578T cells $\left(5 \times 10^{4}\right.$ cells/well) were cultured in the upper compartment of the transwell chamber (BD Biosciences) in serum-free medium. The lower chamber contains $600 \mu \mathrm{l}$ medium (containing $10 \%$ fetal bovine serum). The transwell chambers were coated with $50 \mu \mathrm{l}$ Matrigel, and cell invasion was evaluated at a dilution of 1:5 in serum-free DMEM. After transfection囚place the transfected cells in the upper part of the chamber. Stain the cells for 48 hours. Finally, five random fields under the fluorescence microscope (Olympus Corporation) were selected for each group and had their cell numbers counted.

\subsubsection{Cell apoptosis assay}

Annexin V-FITC/PI Apoptosis Detection Kit (KeyGen Biotech) was used to detect cell apoptosis. After 24 hours of transfection, $1 \times 10^{5}$ cells were made into $100 \mu$ l solution with culture medium and transferred to a centrifuge tube.Flow cytometry detection was performed for Annexin V-FITC and PI using a LSRFortessaFlow Cytometer (Becton Dickinson).

\subsubsection{Bioinformatics analysis}

The expression of miR-324-5p in BC is searched for online database The Cancer Genome Atlas. The miR324-5p target gene is combined with Targetscan, miRDB and miRtarbase databases. Inclusion criteria requires at least three databases. The expression of miR-324-5p and the correlation between such expression and BC were analyzed via StarBase and GEPIA.

\subsubsection{Statistical analyses}

Prism 9.0 software (GraphPad Software) was used to analyze the data. The relative quantification of miR-324-5p was calculated by the $2^{-\Delta \Delta C t}$ method. SPSS was used for the COX regression analysis. ${ }^{*}, p \square$ $0.05, * \star, p \otimes 0,01, \star \star \star,, p \otimes 0,001$.

\section{Results}

\subsubsection{MiR-324-5p expression in BC tissue}

We first analyzed miR-324-5p expression in 1,103 BC patients included in The Cancer Genome Atlas (TCGA) database (Fig. 1A) to confirm whether the miR324-5P expression in BC was disordered. By comparing the results obtained from $41 \mathrm{BC}$ breast lesion samples and 41 adjacent normal samples, we confirmed that miR-324-5p levels increased in BC (Fig. 1B). The miR-324-5P expression was relatively higher in patients with positive lymph node metastasis and advanced breast cancer冈Fig. 1C-D区. Overall, the data showed that miR-324-5p might promote BC progression.

\subsubsection{Expression and diagnostic value of serum miR-324-5p in BC.}

The miR-324-5p relative expression in BC serum $(n=104)$ and normal serum $(n=50)$ was detected by reverse transcription-quantitative polymerase chain reaction (RT-qPCR), which revealed that BC 
serum contained higher miR-324-5p levels than the normal serum (Fig. 2A). After evaluating the potential of serum miR-324-5p levels as a diagnostic biomarker for BC, further evaluation results showed that the receiver operating characteristic (AUC) value for the miR-324-

$5 p$ based diagnosis of $\mathrm{BC}$ was 0.7581 (95\% confidence interval (Cl: $0.6828-0.8335)$, the sensitivity was $66 \%$, and the specificity was $78 \%$. (Figure $2 \mathrm{~B}$ ).

3.1.3 Correlation between clinicopathological features and miR-324-5p expression in patients with BC

We analyzed whether miR-324-5p in serum had significant differential expressions due to different clinicopathological features. Patients were categorized into a high expression (miR-324-5p expression in serum > 4.36) and a low expression (miR-324-5p expression in serum < 4.36) groups. The results showed that the high miR-324-5p expression was not related to age, tumor size and lymph node metastasis, human epithelial growth factor receptor 2, estrogen receptor, progesterone receptor or type, Ki-67 but is correlated with the specific TNM stage $₫ p=0.0291)$ and age $(p=0.0278)$ (Table 1$)$.

\subsubsection{Serum miR-324-5p prognostic value for BC}

In survival analysis, patients with low miR-324-5P had a significantly better 5-year DFS ( $p=0.027$; Figure $3 A)$ and OS ( $p=0.017$; Figure 3B) than the high miR-324-5P group. However, miR-324-5p (HR: 2.256; $95 \%$ Cl:1.06-4.802; $p=0.035)$, TNM stage (HR:3.622; 95\% Cl:1.682-7.798; $p=0.001)$, and Ki-67 (HR: 2.818; 95\% Cl:1.164-6.826; $p=0.022$ ) were significantly associated with DFS. MiR-324-5p (HR: 2.722; 95\% Cl:1.0616.983; $p=0.037$ ), TNM stage (HR: 3.791; 95\% Cl:1.632-8.804; $p=0.002)$, and Ki-67 (HR: 3.59; 95\% Cl:1.136$11.345 ; p=0.029$ ) which are independent prognostic factors for OS in the multivariate analysis (Table 2 and Table3).

\subsubsection{MiR-324-5p promoted the proliferation and inhibited apoptosis of BC cells}

We further analyzed miR-324-5p expression in BC cells (MCF-7, Hs578T, and T-47D) and found a significant increase in miR-324-5p expression compared to human breast epithelial cells (MCF-10A) (Fig.4A). The MCF-7 and Hs578T cell lines were transfected with agomiR-324-5p/antagomiR-324$5 p$ to reveal whether miR-324-5p dysregulation would influence BC cell function and to induce miR-324$5 p$ overexpression or inhibition. We transfected negative control miRNA (Fig. 4B). The CCK-8 assay and Cloning experiment result (Fig. 4C-D) showed that miR-324-5p overexpression enhanced the MCF-7 cells proliferation, while the growth potential of Hs578T cells with inhibited miR-324-5p expression was weakened. As expected, the Hs578T cells apoptosis level increased with miR-324-5p inhibition, while the MCF-7 cells apoptosis decreased with miR-324-5p overexpression (Fig. 4E-F). These results indicate that miR-324-5p may promote proliferation and inhibit BC cells apoptosis.

\subsubsection{MiR-324-5p promoted BC cell migration and invasion}

The wound healing results showed that the miR-324-5p up-regulation could stimulate wound closure after $24 \mathrm{~h}$ of scratch injury in MCF-7 cells. However, in Hs578T cells the inhibitory expression of miR-324-5p had a contrasting effect (Fig. 5A-B). In addition, attenuating the miR-324-5p expression can inhibit the 
migration and invasion of HS578T cells, while a miR-324-5p mimic can enhance MCF-7 cells, as shown in Fig. 5C-D. These results indicate that miR-324-5p has a positive effect on BC cells migration and invasion.

\subsubsection{MiR-324-5p target genes exploration}

Next, our research on miR-324-5p explored the possible molecular regulation mechanisms. We used online bioinformatics databases to find potential miR-324-5p target genes. Ten genes appeared in the miDBR, TargetScan, and miRTarBase databases (Fig. 6A). These genes included CDP-diacylglycerol synthase 1 (CDS1), CUE domain-containing 2 (CUEDC2), cysteine-rich hydrophobic domain 1 (CHIC1), kruppel like factor 7 (KLF7), the mediator of cell motility 1 (MEM01), ras-related nuclear protein (RAN), sublingual immunotherapy (SLIT), neurotrophic tropomyosin-receptor kinase (NTRK)-like family member 4 (SLITRK4), specific protein 1 (SP1), YOD1 deubiquitinase (YOD1), transmembrane and coiled-coil domain family 1 (TMCC1). There is an inverse correlation between target genes and miRNA expression. In the starBase database (Fig. 6B-K), we observed that CDS1, CHIC1, CUEDC2, KLF7, SP1, and SLITTK4 genes in $B C$ were negatively correlated with miR-324-5p. We used the Kaplan-Meier plotter to evaluate miR-324-5p in relation to the six genes and their prognostic role in BC. In BC, a high expression of miR324-5p indicates an adverse prognosis, but a high expression of CHIC1, KLF7, and CUEDC2 is a better prognostic indicator (Fig. 7A-E). Subsequently, the expression of these three genes in BC was analyzed with the Gene expression profiling interactive analysis (GEPIA) database, and the results showed that CHIC1 and KLF7 are valuable (Fig. 7F-H). However, CUEDC2 revealed no significant differences in its expression between $\mathrm{BC}$ and normal breast tissues. Based on these findings, we propose a potential miR324-5p-mRNA network pathway named miR-324-5p-CHC1/KLF7 to explore BC pathogenesis and progression further.

\section{Discussion}

$\mathrm{BC}$ is the most prevalent tumor that threatens the health of women worldwide [1]. Although there are increasingly new strategies to prevent $\mathrm{BC}$, its incidence and recurrence rates are increasing, illustrating the critical need for early detection and treatment [2]. MiRNAs are widely expressed in eukaryotes, and they participate in tissues and organs development [16], involving the regulation of multiple functions, such as cell proliferation, apoptosis, invasive migration, metabolism, neuronal patterns, immune regulation, and cellular stress responses [17]. Thus, miRNAs have been identified as one of the important factors in human cancer [18]. Some studies report that many miRNAs are unbalanced in BC and either promote or inhibit BC occurrence and metastasis [19-21]. Research has shown that the expression of various miRNAs can be detected in 12 kinds of body fluids, including serum, urine, and saliva, suggesting that miRNA could be detected in a liquid biopsy [22]. Mitchell et al. [23] initially described serum miRNAs, and subsequent in-depth studies suggested that serum miRNA can be used as a biomarker for various malignant tumors, including BC. For example, the diagnostic specificity of miR195 , which is up-regulated in the patients with BC serum, is approximately $90 \%$ [24]. In addition, upregulated serum miR-103 possesses $84 \%$ sensitivity and $70 \%$ specificity, demonstrating its diagnostic 
potential [25]. D. LI found serum exosomal miR-148a as a novel prognostic biomarker for breast cancer [26]. These findings make serum miRNA a promising potential BC biomarker.

Studies have shown that miR-324-5p affects tumor occurrence and development by regulating target genes in various human cancers. MiR-324-5p promotes the progression of thyroid papillary cancer via the PTPRD/CEBPD [13]. In addition, miR-324-5p reduced the tumor protein expression, phosphatase, and tensin homolog and may improve gastric cancer`s invasion and proliferation ability [14]. Furthermore, Wan et al. [15] discovered that miR-324-5p promoted pancreatic cancer progression due to the tumor suppressor gene expression and kruppel-like factor 3.

In this study, we discovered that the miR-324-5p expression in BC tissues increased significantly compared to the normal breast tissues for the first time. Furthermore, the miR-324$5 p$ levels in the tissues of patients with BC and at an advanced stage of TNM or positive lymph node metastasis were higher than those in early-stage patients or negative lymph node metastasis. In addition, we noted that the expression trend of serum miR-324-5p levels was consistent with that in the tissues of patients with BC, suggesting a possibility of miR-324-5p as a BC biomarker. The role of serum miR-324$5 \mathrm{P}$ in the diagnosis and prognosis evaluation of breast cancer was explored. The receiver operating characteristic (AUC) of BC diagnosis based on miR-324-5p was 0.7208 and the sensitivity was $83 \%$. The expression of miR-324-5p was related to TNM stage, progesterone receptor, tumor size and lymph node metastasis. In addition, patients with low expression of miR-324-5P significantly increaseded DFS and OS in 5 years. COX regression showed that miR-324-5p was an independent prognostic factor of OS in multivariate analysis of breast cancer. MiR-324-5P is a sensitive indicator, and its prognostic value is greater than the diagnostic value. The number of serum samples in this study was limited. As a result, the outcomes of the study need to be validated with a larger sample size.

In addition, the mechanism study of miR-324-5P on BC shows that it can promote proliferation, $\mathrm{BC}$ migration and inhibit apoptosis. MiRNAs inhibit the expression of multiple target genes. In this study, 10 genes from the target gene database were selected as candidates to validate miR-324-5p potential target genes and test the miR-324-5p predictive ability in BC. Furthermore, miR-324-5p was inversely correlated with CDS1, CHIC1, CUEDC2, KLF7, SLITRK4, and SP1, CHIC1, CUEDC2, and KLF7 were overexpressed and associated with better prognosis. In addition, we observed that $\mathrm{CHIC1}$ and KLF7 from the GEPIA database were significantly lower in $\mathrm{BC}$ tissues than normal breast tissue. Currently, $\mathrm{CHIC1}$-related diseases include ovarian epithelial tumors and Allan-Herndon-Dudley syndrome. [27]. KLF7 is known as the ubiquitous kruppel-like factor and is a key factor in the development of many cancers and an independent predictor of poor prognosis in several cancers [28]. In vitro, functional experiments have shown that KLF7 can affect tumor proliferation and migration [29-31]. Therefore, miR-324-5p may target CHIC1 and KLF7 to facilitate the progression of $\mathrm{BC}$, resulting in a decreased survival rate of $\mathrm{BC}$ patients.

\section{Conclusion}


In conclusion, the serum miR-324-5p expression may be used as a biomarker for the $\mathrm{BC}$ diagnosis and prognosis. MiR-324-5p may promote the occurrence and development of $\mathrm{BC}$ cells by inhibiting the $\mathrm{CHC} 1$ and KLF7.

\section{Declarations}

Ethics approval and consent to participate

Written informed consent was signed by all breast cancer patients and volunteers. This study was approved by the Ethics Committee of Shaoxing People's Hospital and conducted according to the guidelines of Helsinki Declaration.

Consent for publication

Not applicable

Availability of data and materials

The data sets used and/or analyzed during the current study are available from the corresponding author on reasonable request.

Competing interests

The authors declare that they have no competing interests

Funding

The present study was supported by the Public Technology Research Project of Zhejiang Province (grant no. LGF18H200006) and the Medicines Health Technology Plan Project of Zhejiang Province (grant no. 2018PY073), Shaoxing municipal medical and health science and technology plan project $₫$ grant no. 2020A13007凶.

Authors' contributions

$\mathrm{JZ}$ and $\mathrm{AL}$ have made great contributions to the concept and design. JZ and $\mathrm{YZ}$ are responsible for collecting specimens and analyzing clinical data. SL, HW and LG contributed to the writing, review and/or revision of manuscripts. And xdlz producer manuscript. All authors have read and approved the final manuscript.

Acknowledgements

Not applicable

\section{References}


1 Erratum: Global cancer statistics 2018: GLOBOCAN estimates of incidence and mortality worldwide for 36 cancers in 185 countries. CA Cancer J Clin. 70(4):313,2020. PMID: 32767693.DOI:

10.3322/caac. 21609 .

2 Knudsen BS, Kim HL, Erho N, Shin H, Alshalalfa M, Lam LLC, Tenggara I, Chadwich K, Van Der Kwast T, Fleshner N, Davicioni E, Carroll PR, Cooperberg MR, Chan JM, Simko JP:Application of a Clinical WholeTranscriptome Assay for Staging and Prognosis of Prostate Cancer Diagnosed in Needle Core Biopsy Specimens. J Mol Diagn. 18(3):395-406, 2016. PMID: 26945428.DOI: 10.1016/j.jmoldx.2015.12.006.

3 Aalami AH, Pouresmaeil V, Amirabadi A, Mojahed FH, Rad MQ, Sahebkar A:Evaluation of the Diagnostic Properties of Serum hsa-miR-223-5p in the Detection of Gastric Cancer: A Case-Control Study. Anticancer Agents Med Chem. 20(7):800-808,2020. PMID: 32013852.DOI: 10.2174/1871520620666200204100602.

4 Li P, Xie XB, Chen Q, Pang GL, Luo W, Tu JC, Zheng F, Liu SM, Han L, Zhang JK, Luo XY, Zhou X: MiRNA15a mediates cell cycle arrest and potentiates apoptosis in breast cancer cells by targeting synuclein-y. Asian Pac J Cancer Prev. 15(16):6949-54,2014.PMID: 25169552. DOI: 10.7314/apjcp.2014.15.16.6949.

5 Yan R, Yang T, Zhai H, Zhou Z, Gao L, Li Y:MicroRNA-150-5p affects cell proliferation, apoptosis, and EMT by regulation of the BRAFV600E mutation in papillary thyroid cancer cells. J Cell Biochem.119(11):8763-8772,2018.PMID: 30126001.DOI: 10.1002/jcb.27108.

6 Yang Z, Zhang T, Wang Q, Gao H:Overexpression of microRNA-34a Attenuates Proliferation and Induces Apoptosis in Pituitary Adenoma Cells via SOX7. Mol Ther Oncolytics. 9;10:40-47,2018. PMID: 30109259.DOI: 10.1016/j.omto.2018.07.001.

7 Xiao R, Li C, Chai B:miRNA-144 suppresses proliferation and migration of colorectal cancer cells through GSPT1. Biomed Pharmacother. 74:138-44,2015. PMID: 26349975.DOI:

10.1016/j.biopha.2015.08.006.PMID: 26349975.

8 Iranzad R, Motavalli R, Ghassabi A, Pourakbari R, Etemadi J, Yousefi M:Roles of microRNAs in renal disorders related to primary podocyte dysfunction. Life Sci. 15;277:119463,2021. PMID: 33862110.DOI: 10.1016/j.lfs.2021.119463.

9 Xiong X, Xu W, Gong J, Wang L, Dai M, Chen G, Yuan L:miR-937-5p targets SOX17 to modulate breast cancer cell cycle and cell proliferation through the Wnt signaling pathway. Cell Signal.

77:109818,2021.PMID: 33144185.DOI: 10.1016/j.cellsig.2020.109818. PMID: 33144185.

10 Noyan S, Andac Ozketen A, Gurdal H, Gur Dedeoglu B: miR-770-5p regulates EMT and invasion in TNBC cells by targeting DNMT3A. Cell Signal. 83:109996,2021. PMID: 33798630.DOI: 10.1016/j.cellsig.2021.109996.

11 Zhang X, Zhang L, Chen M, Liu D: miR-324-5p inhibits gallbladder carcinoma cell metastatic behaviours by downregulation of transforming growth factor beta 2 expression. Artif Cells Nanomed 
Biotechnol.48(1):315-324,2020.PMID:31858815.DOI:10.1080/21691401.2019.1703724.

12 Gu C, Zhang M, Sun W, Dong C:Upregulation of miR-324-5p Inhibits Proliferation and Invasion of Colorectal Cancer Cells by Targeting ELAVL1. Oncol Res. 7;27(5):515-524,2019. PMID: 29386086.DOI: 10.3727/096504018X15166183598572.

13 Yang Y, Xia S, Zhang L, Wang W, Chen L, Zhan W:MiR-324-5p/PTPRD/CEBPD axis promotes papillary thyroid carcinoma progression via microenvironment alteration. Cancer Biol Ther. 2;21(6):522-532,2020. PMID: 32151175.DOI: 10.1080/15384047.2020.1736465.

14 Zheng Z, Li J, An J, Feng Y, Wang L:High miR-324-5p expression predicts unfavorable prognosis of gastric cancer and facilitates tumor progression in tumor cells. Diagn Pathol.11;16(1):5,2021. PMID: 33430926.DOI: 10.1186/s13000-020-01063-2.

15 Wan Y, Luo H, Yang M, Tian X, Peng B, Zhan T, Chen X, Ding Y, He J, Cheng X, Huang X, Zhang Y:miR324-5p Contributes to Cell Proliferation and Apoptosis in Pancreatic Cancer by Targeting KLF3. Mol Ther Oncolytics. 31;18:432-442,2020. PMID: 32913892.DOI: 10.1016/j.omto.2020.07.011.

16 Barbosa M, Gomes C, Sequeira C, Gonçalves-Ribeiro J, Pina CC, Carvalho LA, Moreira R, Vaz SH, Vaz AR, Brites D:Recovery of Depleted miR-146a in ALS Cortical Astrocytes Reverts Cell Aberrancies and Prevents Paracrine Pathogenicity on Microglia and Motor Neurons. Front Cell Dev Biol.23;9:634355,2021. PMID: 33968923.DOI: 10.3389/fcell.2021.634355.

17 Hong X, Wang J, Li S, Zhao Z, Feng Z:MicroRNA-375-3p in endothelial progenitor cells-derived extracellular vesicles relieves myocardial injury in septic rats via BRD4-mediated PI3K/AKT signaling pathway. Int Immunopharmacol. 96:107740,2021.PMID: 34020393. DOI: 10.1016/j.intimp.2021.107740.

18 Matsui T, Hamada-Tsutsumi S, Naito Y, Nojima M, lio E, Tamori A, Kubo S, Ide T, Kondo Y, Eguchi Y, Komori A, Morine Y, Shimada M, Utsunomiya T, Shirabe K, Kimura K, Hiasa Y, Chuaypen N, Tangkijvanich P, Naiki-Ito A, Takahashi S, Ochiya T, Tanaka Y:Identification of microRNA-96-5p as a postoperative, prognostic microRNA predictor in nonviral hepatocellular carcinoma. Hepatol Res.26,2021. PMID: 34038612.DOI: 10.1111/hepr.13674.

19 Borzi C, Ganzinelli M, Caiola E, Colombo M, Centonze G, Boeri M, Signorelli D, Caleca L, Rulli E, Busico A, Capone I, Pastorino U, Marabese M, Milione M, Broggini M, Garassino MC, Sozzi G, Moro M:LKB1 Down-Modulation by miR-17 Identifies Patients With NSCLC Having Worse Prognosis Eligible for EnergyStress-Based Treatments. J Thorac Oncol. 16(8):1298-1311,2021. PMID: 33887464.DOI:

10.1016/j.jtho.2021.04.005.

20 Zhu Y, Wang Q, Xia Y, Xiong X, Weng S, Ni H, Ye Y, Chen L, Lin J, Chen Y, Niu H, Chen X, Lin Y:Evaluation of MiR-1908-3p as a novel serum biomarker for breast cancer and analysis its oncogenic function and target genes. BMC Cancer.10;20(1):644,2020. PMID: 32650755.DOI: 10.1186/s12885-020-07125-4. 
$21 \mathrm{Hu}$ Y, Wu D, Feng X, Shi Z:Research on the effect of interfering with miRNA-155 on triple-negative breast cancer cells. Genes Genomics.28,2021. PMID: 33909229.DOI: 10.1007/s13258-021-01106-y.

22 Matsuzaki K, Fujita K, Tomiyama E, Hatano K, Hayashi Y, Wang C, Ishizuya Y, Yamamoto Y, Hayashi T, Kato T, Jingushi K, Kawashima A, Ujike T, Nagahara A, Uemura M, Tsujikawa K, Nonomura N:MiR-30b-3p and miR-126-3p of urinary extracellular vesicles could be new biomarkers for prostate cancer. Transl Androl Urol. 10(4):1918-1927,2021. PMID: 33968679.

DOI: 10.21037/tau-20-421.

23 Sebastiani G, Nigi L, Grieco GE, Mancarella F, Ventriglia G, Dotta F:Circulating microRNAs and diabetes mellitus: a novel tool for disease prediction, diagnosis, and staging? J Endocrinol Invest.40(6):591610,2017. PMID: 28213644.DOI: 10.1007/s40618-017-0611-4.

24 Zhao FL, Dou YC, Wang XF, Han DC, Lv ZG, Ge SL, Zhang YK:Serum microRNA-195 is down-regulated in breast cancer: a potential marker for the diagnosis of breast cancer. Mol Biol Rep. 41(9):591322,2014.PMID: 25103018.DOI: 10.1007/s11033-014-3466-1.

25 Wang X, Wu X, Yan L, Shao J: [Serum miR-103 as a potential diagnostic biomarker for breast cancer]. Nan Fang Yi Ke Da Xue Xue Bao. 32(5):631-4,2012. Chinese. PMID: 22588912.

26 Li D, Wang J, Ma LJ, Yang HB, Jing JF, Jia MM, Zhang XJ, Guo F, Gao JN:Identification of serum exosomal miR-148a as a novel prognostic biomarker for breast cancer. Eur Rev Med Pharmacol Sci. 24(13):7303-7309,2020.PMID: 32706068.DOI: 10.26355/eurrev_202007_21889.

27 Miller BT, Rubino DM, Driggers PH, Haddad B, Cisar M, Gray K, Segars JH:Expression of brx protooncogene in normal ovary and in epithelial ovarian neoplasms. Am J Obstet Gynecol.182(2):28695,2000.PMID:10694326. DOI:10.1016/s0002-9378(00)70213-4.

28 Niu R, Tang Y, Xi Y, Jiang D:High Expression of Krüppel-like Factor 7 Indicates Unfavorable Clinical Outcomes in Patients with Lung Adenocarcinoma. J Surg Res.250:216-223,2020.PMID: 32092599.DOI: 10.1016/j.jss.2019.12.053.

29 Jiang Z, Yu T, Fan Z, Yang H, Lin X:Krüppel-Like Factor 7 is a Marker of Aggressive Gastric Cancer and Poor Prognosis. Cell Physiol Biochem.43(3):1090-1099,2017.PMID: 28977783.DOI: 10.1159/000481748.

30 Guan F, Kang Z, Zhang JT, Xue NN, Yin H, Wang L, Mao BB, Peng WC, Zhang BL, Liang X, Hu ZQ:KLF7 promotes polyamine biosynthesis and glioma development through transcriptionally activating ASL. Biochem Biophys Res Commun.18;514(1):51-57,2019.PMID: 31018905.DOI: 10.1016/j.bbrc.2019.04.120.

31 Zhao L, Zhang Y, Liu J, Yin W, Jin D, Wang D, Zhang W:miR-185 Inhibits the Proliferation and Invasion of Non-Small Cell Lung Cancer by Targeting KLF7. Oncol Res.23;27(9):1015-1023,2019. PMID: 29716672.DOI: 10.3727/096504018X15247341491655. 


\section{Tables}

Table III Univariate and multivariate analysis of the prognostic variables influencing overall survival in breast cancer patients.

\begin{tabular}{|c|c|c|c|c|}
\hline \multirow[b]{2}{*}{ Variables } & \multicolumn{2}{|c|}{ Univariate analysis } & \multicolumn{2}{|c|}{ Multivariate analysis } \\
\hline & $\mathrm{HR} \otimes 95 \% \mathrm{Cl} \rrbracket$ & $\mathrm{p}$-value & $\mathrm{HR} \rrbracket 95 \% \mathrm{Cl} \rrbracket$ & $\begin{array}{l}\mathrm{p} \text { - } \\
\text { value }\end{array}$ \\
\hline Age $₫ \leq 54$ vs $₫ 55 \rrbracket$ & $\begin{array}{l}0.954 \rrbracket 0.428- \\
2.123 \rrbracket\end{array}$ & 0.907 & NA & NA \\
\hline Tumor size( $\leq 2$ vs $\otimes 2$ ) & $\begin{array}{l}2.391(0.991- \\
5.767)\end{array}$ & 0.052 & NA & NA \\
\hline 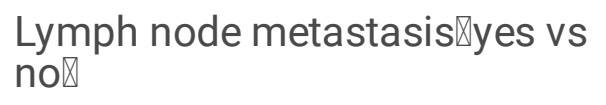 & $\begin{array}{l}2.242(0.996- \\
5.049)\end{array}$ & 0.051 & NA & NA \\
\hline 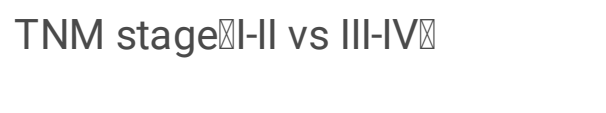 & $\begin{array}{l}4.387(1.911- \\
10.068)\end{array}$ & $<0.0001$ & $\begin{array}{l}3.791(1.632- \\
8.804)\end{array}$ & 0.002 \\
\hline ER status(negative vs positive) & $\begin{array}{l}0.687 \rrbracket 0.284- \\
1.659 \rrbracket\end{array}$ & 0.404 & NA & NA \\
\hline PR status(negative vs positive) & $\begin{array}{l}0.392 \rrbracket 0.174- \\
0.883 \rrbracket\end{array}$ & 0.024 & $\begin{array}{l}0.684(0.282- \\
1.655)\end{array}$ & 0.399 \\
\hline $\begin{array}{l}\text { HER2 status(negative vs } \\
\text { positive) }\end{array}$ & $\begin{array}{l}0.655 \rrbracket 0.244- \\
1.756 \rrbracket\end{array}$ & 0.4 & NA & NA \\
\hline Type囚LUM vs NLUM $\otimes$ & $\begin{array}{l}1.996(0.984- \\
4.048)\end{array}$ & 0.055 & NA & NA \\
\hline $\mathrm{Ki}-67(\leq 30$ vs $\otimes 30)$ & $\begin{array}{l}3.993(1.364- \\
11.686)\end{array}$ & 0.012 & $\begin{array}{l}3.59(1.136- \\
11.345)\end{array}$ & 0.029 \\
\hline $\begin{array}{l}\text { miR-324-5P expression(low vs } \\
\text { high) }\end{array}$ & $\begin{array}{l}3.224(1.279- \\
8.128)\end{array}$ & 0.013 & $\begin{array}{l}2.722(1.061- \\
6.983)\end{array}$ & 0.037 \\
\hline
\end{tabular}

\section{Figures}

\section{Figure 1}


Table 1 Clinicopathological variables and the serum expression of miR-324-5p in BC

Factors Total $\llbracket n=100 \rrbracket \quad$ miR-324-5p expression $p$-value $\operatorname{High}(\mathrm{n}=50) \quad \operatorname{Low}(\mathrm{n}=50) \quad$ (chi-square test)

Age

$\leq 54$ years

49

30

19

0.0278

$>54$ years

51

20

31

Tumor size

$\leq 2 \mathrm{~cm}$

47

23

24

0.8412

$>2 \mathrm{~cm}$

53

27

26

Lymph node metastasis

Yes

No

TNM

I/II

III

ER status

Negative

Positive

PR status

Negative

Positive

HER2

Negative

Positive

Type

LUM

NLUM

Ki-67

$<30 \%$
41

59

84

16

24

76

12

12

$>0.9999$

38

38

46

0.0291

12

4

32

18

0.3093

27

0.0291

4

38

39

23

16

0.1512

61

27

34

15

10

5

0.1614

85

40

45

76

37

39

0.6396

24

13

11 
HER2, human epidermal growth factor receptor 2; ER, estrogen receptor; PR, progesterone receptor; LUM, luminal;NLUM,NO-luminal

Table II Univariate and multivariate analysis of the prognostic variables influencing disease-free survival in breast cancer patients.

\begin{tabular}{|c|c|c|c|c|}
\hline & Univariate analysis & & Multivariate analysi & \\
\hline Variables & $\mathrm{HR} \rrbracket 95 \% \mathrm{Cl} \rrbracket$ & $\begin{array}{l}\mathrm{p}- \\
\text { value }\end{array}$ & $\mathrm{HR} \rrbracket 95 \% \mathrm{Cl} \rrbracket$ & $\mathrm{p}$-value \\
\hline Age $₫ \leq 54$ vs $₫ 55 \rrbracket$ & $\begin{array}{l}1.046 \rrbracket 0.522- \\
2.094 \rrbracket\end{array}$ & 0.9 & NA & NA \\
\hline Tumor size( $\leq 2$ vs $\otimes 2$ ) & $\begin{array}{l}1.903 \rrbracket 0.917- \\
3.949 \rrbracket\end{array}$ & 0.084 & NA & NA \\
\hline $\begin{array}{l}\text { Lymph node metastasisđyes vs } \\
\text { no }\end{array}$ & $\begin{array}{l}1.387 \rrbracket 0.692- \\
2.777 \rrbracket\end{array}$ & 0.356 & NA & NA \\
\hline TNM stage『I-II vs III-IV】 & $\begin{array}{l}3.501 \rrbracket 1.652- \\
7.421 \rrbracket\end{array}$ & 0.001 & $\begin{array}{l}3.622 \rrbracket 1.682- \\
7.798 \rrbracket\end{array}$ & 0.001 \\
\hline ER status(negative vs positive) & $\begin{array}{l}0.585 \rrbracket 0.227- \\
1.236 \rrbracket\end{array}$ & 0.16 & NA & NA \\
\hline PR status(negative vs positive) & $\begin{array}{l}0.453 \rrbracket 0.226- \\
0.909 \rrbracket\end{array}$ & 0.026 & $0.626 \rrbracket 0.3-1.308 \rrbracket$ & 0.213 \\
\hline HER2 status(negative vs positive) & $\begin{array}{l}0.688 \rrbracket 0.283- \\
1.672 \rrbracket\end{array}$ & 0.409 & NA & NA \\
\hline 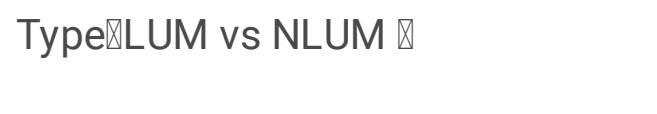 & $\begin{array}{l}1.912 \varangle 0.993- \\
3.682 \rrbracket\end{array}$ & 0.053 & NA & NA \\
\hline Ki- $67(\leq 30$ vs $\otimes 30)$ & $\begin{array}{l}2.994 \rrbracket 1.294- \\
6.926 \rrbracket\end{array}$ & 0.01 & $\begin{array}{l}2.818 \rrbracket 1.164- \\
6.826 \rrbracket\end{array}$ & 0.022 \\
\hline $\begin{array}{l}\text { miR-324-5P expression(low vs } \\
\text { high) }\end{array}$ & $2.473 \rrbracket 1.17-5.227 \rrbracket$ & 0.018 & $2.256 \rrbracket 1.06-4.802 \rrbracket$ & 0.035 \\
\hline
\end{tabular}

The dysregulated performance of miR-324-5p in BC tissue.

(A) In the TCGA database, the expression results of miR-324-5p in BC tissues. (B) Analysis of miR-324-5p expression difference between $B C$ and paracancerous tissues in 41 pairs. (C) The expression difference of miR-324-5p between negative and positive lymph node metastasis (D) The expression difference of miR-324-5p in early and late stages. 
A

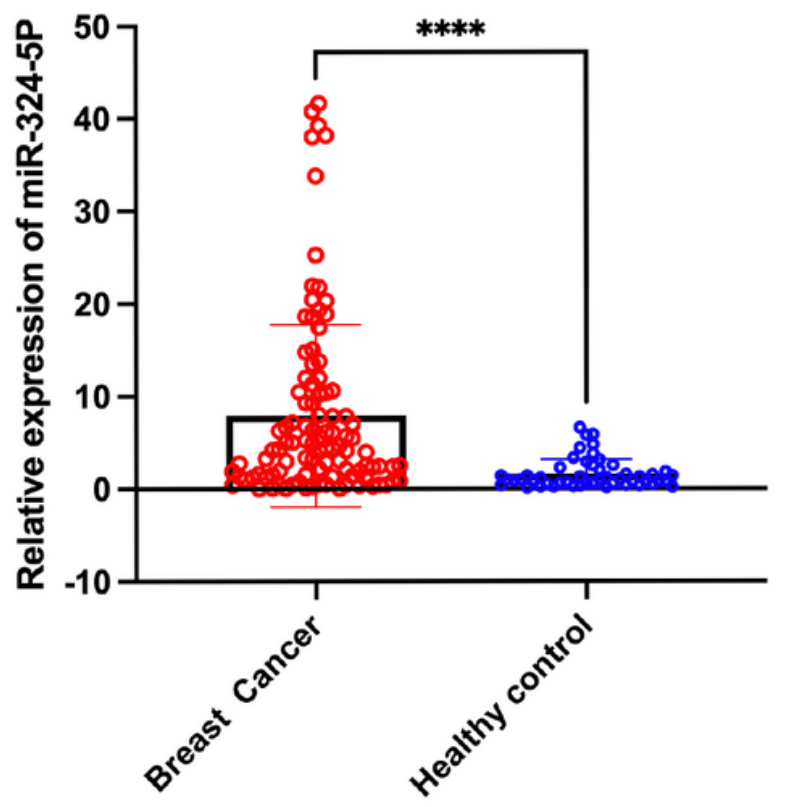

B

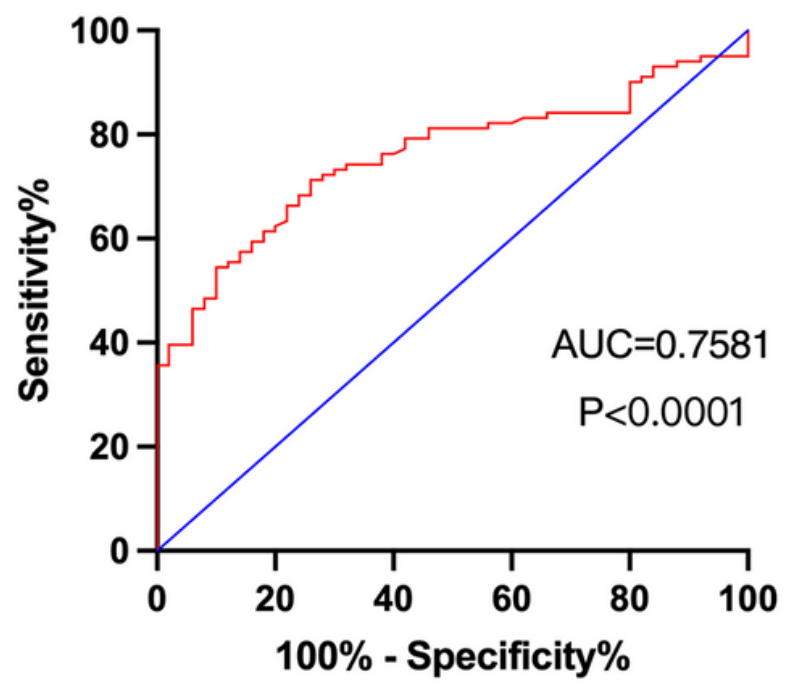

Figure 2

Expression and diagnostic value of serum miR-324-5p in BC

(A) The abundance of miR-324-5p in BC serum and normal serum, measured by RT-qPCR. (B) The ROC analysis of miR-324-5p for the diagnosis of BC. 

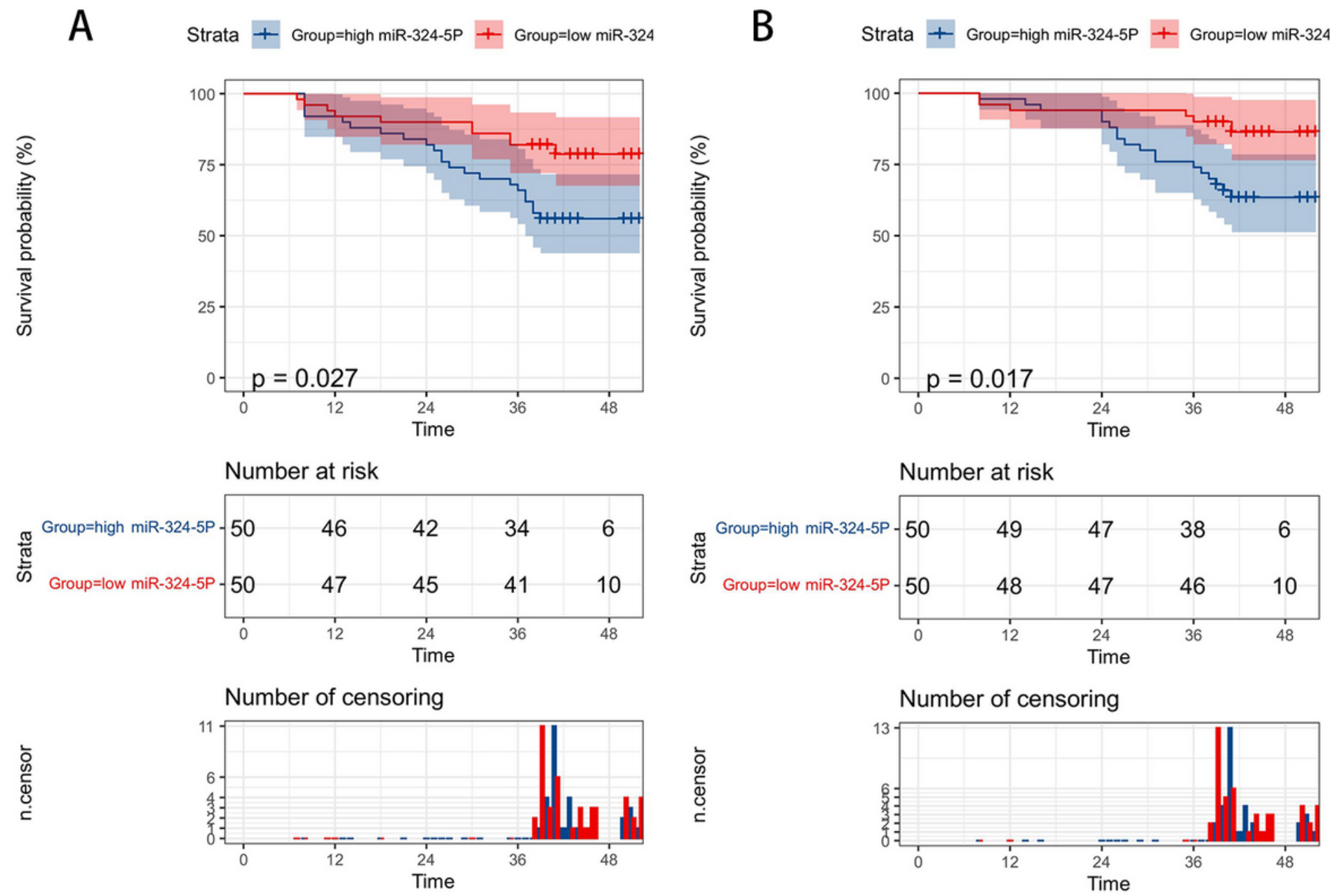

\section{Figure 3}

Relationship between miR-324-5P and survival.

(A) The disease-free survival in the miR-324-5P low expression group was higher than that in the miR-324$5 \mathrm{P}$ high expression group. (B) The overall survival in the miR-324-5P low expression group was higher than that in the miR-324-5P high expression group.

\section{Figure 4}

Study on the effect of miR-324-5p on proliferation and apoptosis of BC cells. (A) The expression of miR324-5p in breast epithelial cells (MCF-10A) and tumor cell lines (MCF-7, T-47D, Hs578T). (B) Validation of the transfection efficacy of the overexpression/inhibition of miR-324-5p. (C-D) The Cell Counting Kit-8 detects the proliferation level. $(\mathrm{E}-\mathrm{F})$ The result of detecting apoptotic rates using flow cytometry. 
The effect of miR-324-5p in promoting cancer migration and invasion $₫ A-B \otimes T h e$ effect of miR-324-5p on the wound healing ability of Hs578T and MCF-7 cells for $24 \mathrm{~h}$, determined by a scarification test. $\mathbb{C} \mathrm{C}-\mathrm{DQ}$ The effect of miR-324-5p on the invasive and migratory abilities of Hs578T and MCF-7 cells for $24 \mathrm{~h}$, observed by transwell assays.
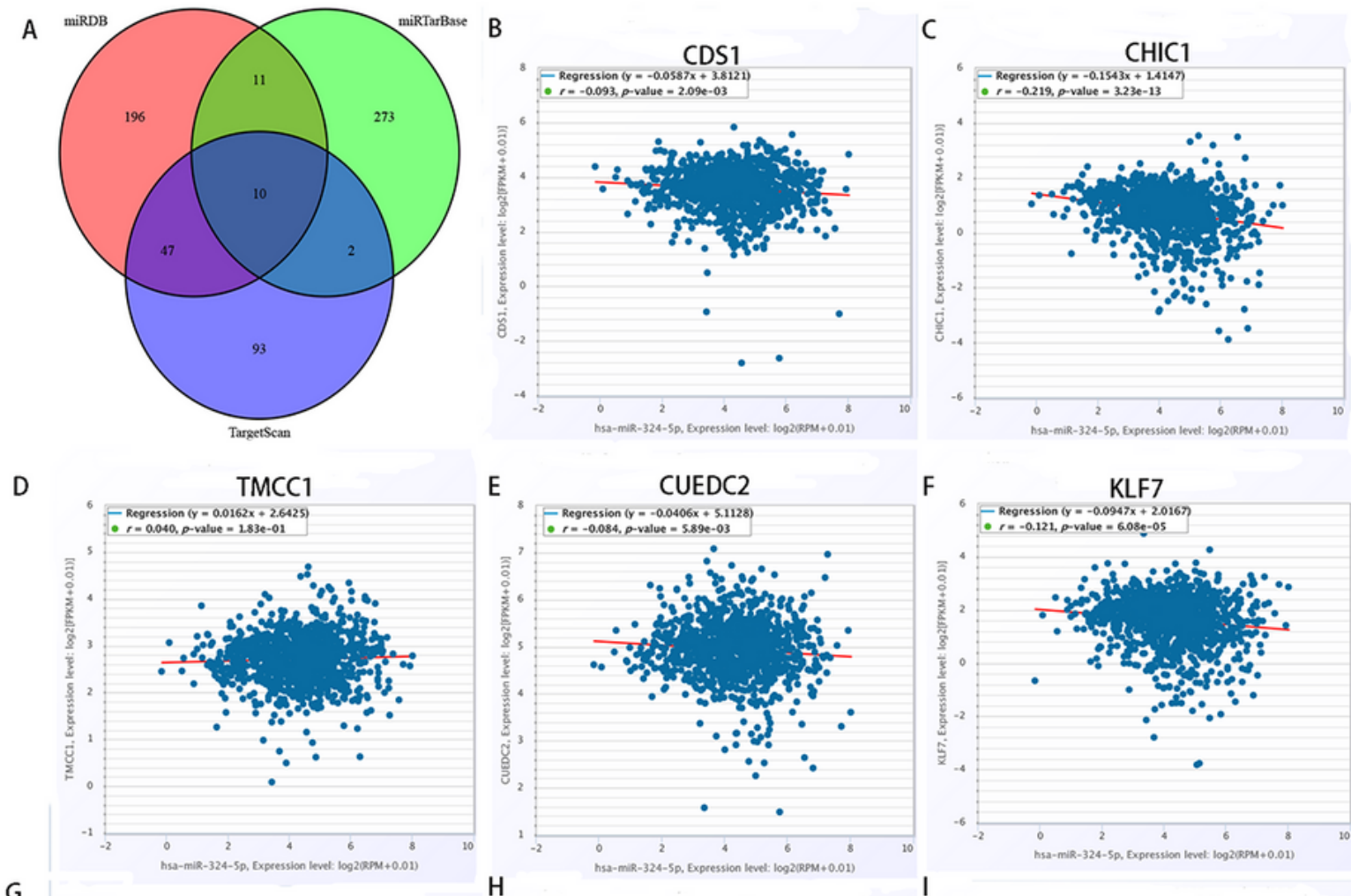

G
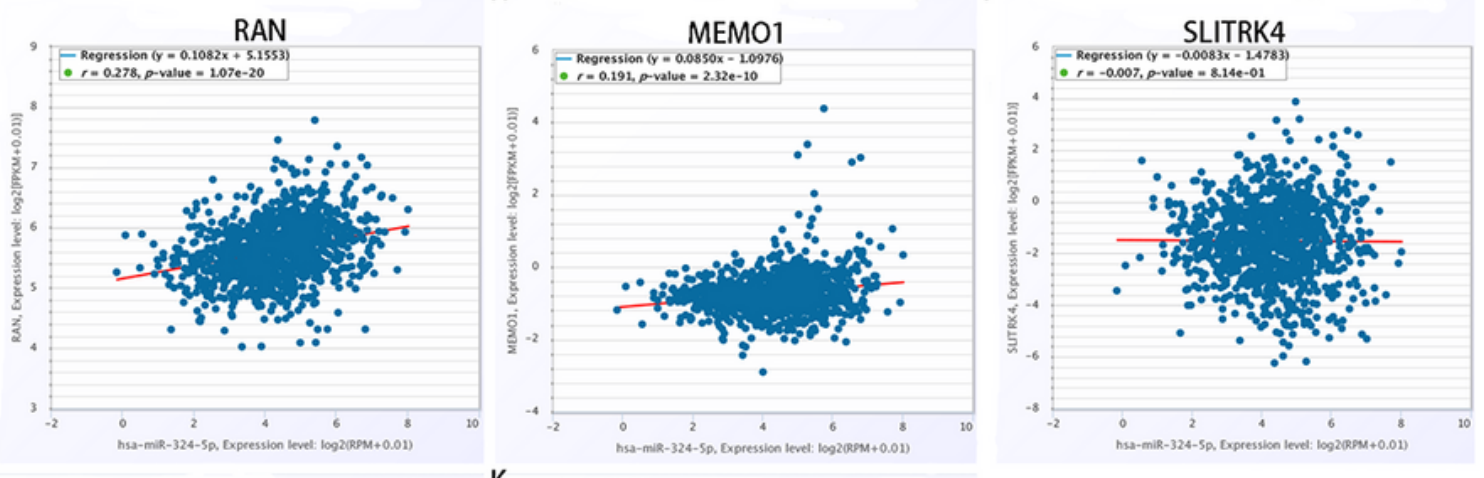

J

K
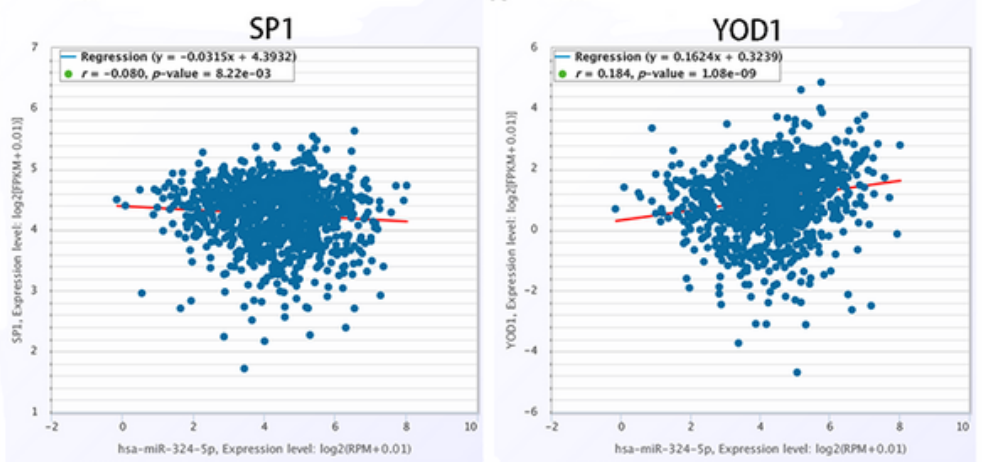

Figure 6 
Identification of miR-324-5p targeted genes in BC. (A) Venn diagram of the intersection of three target gene prediction databases. (B-K) Correlation data between target genes and miR-324-5p in the starBase database.
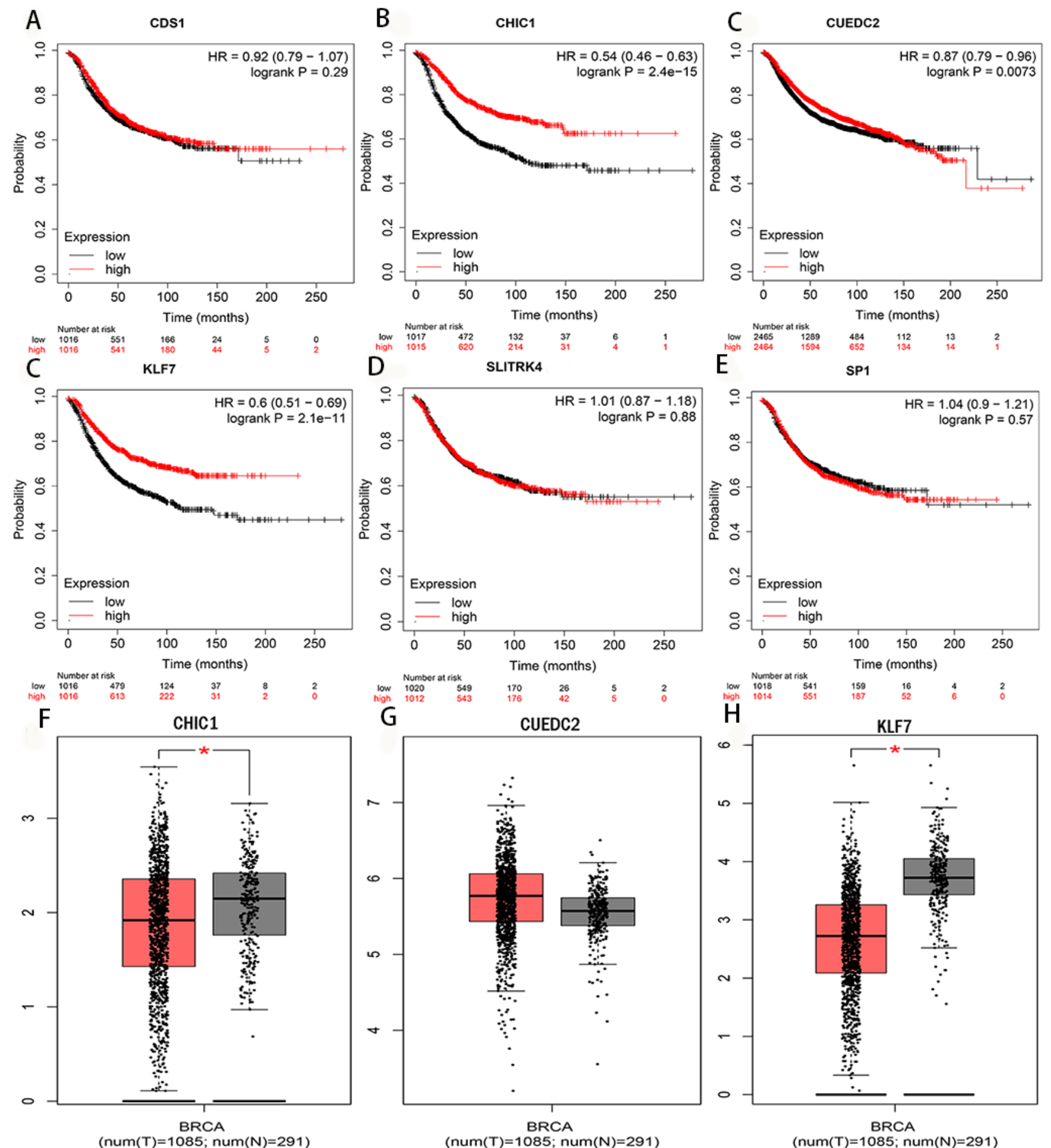

Figure 7 
Further authentication of the targeting relationship between target genes and miR-324-5p.『A-EQThe prognostic analysis of miR-324-5p in relation to CDS1, CHIC1, CUEDC2, KLF7, SP1, and SLITRK4 shown by the Kaplan-Meier plotter.『F-H囚The expression of target genes (CUEDC2, KLF7, and CHIC1) in BC, obtained from the GEPIA database. 